\title{
Enhanced electrical and mechanical properties of rubber/graphene film through layer-by-layer electrostatic assembly
}

\author{
Lei Wang ${ }^{\text {a, }}$, Wencai Wang ${ }^{\text {a, b }}$, Ye Fu ${ }^{\text {a, b, c }}$, Junjun Wang ${ }^{\text {a, }}$, Yuri Lvov ${ }^{\text {d, e, * }}$, Jun Liu ${ }^{\text {a, b, c, * }}$, \\ Yonglai Lu ${ }^{\text {a, b, c, * }}$ and Liqun Zhang ${ }^{\text {a, b, c }}$ \\ ${ }^{a}$ State Key Laboratory of Organic-Inorganic Composites, Beijing University of Chemical Technology, Beijing \\ 100029, China \\ ${ }^{\mathrm{b}}$ Beijing Engineering Research Center of Advanced Elastomers, Beijing 100029, China \\ ${ }^{c}$ Engineering Research Center of Elastomer Materials on Energy Conservation and Resources, Ministry of \\ Education, Beijing 100029, China \\ ${ }^{\mathrm{d}}$ Institute for Micromanufacturing, Louisiana Tech University, Ruston, Louisiana 71270, United States \\ ${ }^{\mathrm{e}}$ Ural Federal University, Ekaterinburg, Russia
}

\begin{abstract}
Despite a large amount of work have been carried out to prepare polymer/graphene hybrid nanocomposites, preparing rubber composites filled with graphene oxide via layer by layer (LBL) electrostatic self-assembly has not yet been reported. In this work, free-standing conductive multilayer film of (PEI/XNBR/PEI/GO) $)_{30}$ (30 is referred to the number of deposition cycles) was fabricated on glass substrate through alternative LBL self-assembly with graphene oxide (GO), carboxylic acrylonitrile butadiene rubber (XNBR) latex, and polyethyleneimine (PEI). During the self-assembly process, negatively charged carboxyl groups on XNBR latex and GO sheets can be electrostatically bound by positively charged amino groups from PEI molecules. After thermal treatment, XNBR latex particles in each layer are gradually mixed together and became a continuous rubber film layer, and partial ionic bonds among XNBR latex, PEI and GO sheets are changed into covalent amide bonds. The formation of the multilayer XNBR/graphene film with ordered arrangement of GO sheets and XNBR latex layers was demonstrated by atomic force microscopy (AFM) and scanning electron microscopy (SEM). The obtained XNBR/graphene film exhibited a significant improvement in mechanical properties, namely, 192\% increase of the tensile strength and $215 \%$ increase of the elastic modulus. Besides, electrical conductivity of the prepared multilayer film reached $8.2 \mathrm{E}-03 \mathrm{~S} \cdot \mathrm{cm}^{-1}$ after thermal reduced reaction. Hopefully, this
\end{abstract}

*Corresponding authors: 1j200321039@163.com, luyonglai@mail.buct.edu.cn, ylvov@latech.edu. 
prepared multilayer film may be potentially used as an elastomeric conductive material.

Keywords: A. Layered structures, A. Thin film, B. Elasticity, B. Electrical properties

\section{Introduction}

Graphene, first discovered in 2004 [1], has attracted voluminous attention in the past decade. As many theoretical and experimental researches reported before, graphene possesses many excellent properties such as excellent mechanical properties $[2,3]$, outstanding thermal conductivity [4], large specific surface area [5] and extraordinary electronic transport performance [6]. However, the poor solubility of graphene in both polar and non-polar solvents has great limitations in the preparation and application of graphene-based nanocomposites $[7,8]$. Compared with graphene, graphene oxide (GO) sheets have more potential applications owing to their oxygen containing groups such as carboxylic, hydroxyl, and epoxy [9-12]. These oxygen containing groups make GO form a stable aqueous colloid through electrostatic stabilization [13]. Therefore, GO can be applied in the fabrication of the highly dispersed graphene-based polymer nanocomposites [14]. Inspired by its large specific surface area and lamellar structure, GO sheets may serve as the building blocks to enhance the mechanical and electrical properties of the nanocomposites.

A layer-by-layer (LBL) self-assembly technique [15] has been exploited to fabricate novel, multifunctional hybrid films with predetermined organization of different components with nanometer precision [16]. GO sheets are negatively charged in aqueous solution at $\mathrm{pH} 6.5$, thus they can be employed to prepare desired multifunctional films via LBL electrostatic self-assembly by alternation with cationic polyelectrolytes [17-20]. Through this strategy, precise control over the structures of composites could be realized in nanometer scale. Recently, 
researches on GO sheets have progressed remarkably in a wide variety of applications by LBL self-assembly technique, such as enhancement in mechanical property [19-24], super electrical devices like battery and supercapacitors [27, 28], and gas barrier application [29]. It can be seen that graphene-based nanocomposites via LBL self-assembly possess great potential applications in the area of functional materials.

It is noteworthy that high-structural integrity yet solution-processable graphene sheets have been developed for polymer composites [30-32], and once compounded with elastomers, these sheets can improve both mechanical properties and electrical conductivity [33, 34]. There are mainly three methods which have been used for the fabrication of graphene/rubber nanocomposites: including mechanical blending [35-37], solution mixing [38, 39], and latex co-coagulation [40, 41]. Mechanical blending is widely used in mass production of both laboratory and factory, but it may leads to the aggregation of GO sheets under large filling amount of GO. Although solution mixing produces good dispersion and exfoliation of GO, the process of solvent evaporation will destroy the environment. Latex co-coagulation method involves mixing of latex and other fillers, and then the polymer blends can be co-precipitated by adding flocculants. In this way, GO can be well dispersed in the rubber latex, but the random orientation of GO limits the rubber/graphene compound's application. Currently, few studies are focused on using layer-by-layer self-assembly technology to develop elastomer nanocomposites [42-46]. Generally, researches were mainly focused on the following three aspects: the modification the rubber surface to optimize its resistance to wear [42], biocompatibility with living organism [43-45] and tissue engineering and biomedicine [46]. For instance, Sruanganurak et al. [42] deposited PMMA particles onto the natural rubber (NR) latex film by 
LBL technique to increase the glove's roughness and hardness. Besides, the method of LBL on rubber composites can be applied in biological research area. Christiane et al. [45] found that the LBL film fabricated by poly(allylamine hydrochloride) (PAH) and NR was made of smaller and flattened particles, which was not efficient for the growth and proliferation of normal human fibroblasts. However, no effort in the preparation of graphene/rubber composites by using LBL self-assembly strategy has been made. This strategy allows the assembly of different organic and inorganic building blocks into well-defined composite films with precise control of the film thickness and desired architecture.

In this article, we first demonstrated the successful fabrication of the free-standing multilayer films of alternating negatively charged GO sheets, positively charged polyethyleneimine (PEI), and negatively charged carboxylic acrylonitrile butadiene rubber (XNBR) latex by electrostatic LBL self-assembly. Then, the obtained multilayer films were transformed from insulation state to conductive state by thermal reduction. The growths, morphology, mechanical and electrical behaviors of the multilayer films were investigated in detail.

\section{Experimental section}

\subsection{Materials}

Polyethyleneimine (PEI) (branched, $\mathrm{Mw}=50000,50 \%$ ) was purchased from Sigma. P-type polished single-crystal silicon (111) wafers were procured from Huayan Silicon Materials Company (Zhejiang, China). The quartz slides were produced by Hongjun Optical Instrument Company (Jiangsu, China). Potassium permanganate $\left(\mathrm{KMnO}_{4}, 99.5 \%\right)$, sulfuric acid $\left(\mathrm{H}_{2} \mathrm{SO}_{4}\right.$, $98 \%)$, sodium nitrate $\left(\mathrm{NaNO}_{3}, 99.0 \%\right)$, hydrogen peroxide $\left(\mathrm{H}_{2} \mathrm{O}_{2}, 30 \%\right)$, hydrochloric acid $(\mathrm{HCl}$, 
$37 \%)$, and methanol $\left(\mathrm{CH}_{3} \mathrm{OH}, 99.5 \%\right)$, which were all used for the preparation of graphene oxide (GO), were supplied by Beijing Chemical Reagents Co., Ltd. (China). Carboxylic acrylonitrile butadiene rubber (XNBR) latex (NipolLX550L, acrylonitrile content $\sim 27 \%$, total solid $\sim 45 \%$ ) was provided by Nippon Zeon Corporation (Japan). Natural graphite flakes were supplied by Huadong Graphite Factory (China).

\subsection{Synthesis of GO}

Graphite oxide was prepared by oxidation of natural graphite power according to a modified Hummers' method [47]. Briefly, $50 \mathrm{ml}$ of $\mathrm{H}_{2} \mathrm{SO}_{4}$ was put into a $500 \mathrm{ml}$ three-neck flask in an ice-water bath, meanwhile $1.5 \mathrm{~g}$ natural graphite and $1.5 \mathrm{~g} \mathrm{NaNO}_{3}$ were added into the flask under stirring. Then $6 \mathrm{~g} \mathrm{KMnO}_{4}$ was slowly added into the mixture in order to keep its temperature below $20^{\circ} \mathrm{C}$. Afterwards, the mixture was heated to $35^{\circ} \mathrm{C}$ and maintained for 40 min. Then $69 \mathrm{ml}$ deionized water was slowly added to avoid a high temperature of the solution above $98^{\circ} \mathrm{C}$. The mixture was further stirred for $20 \mathrm{~min}$ at $98^{\circ} \mathrm{C}$, then $170 \mathrm{~mL}$ deionized water and $35 \mathrm{~mL} \mathrm{H}_{2} \mathrm{O}_{2}(30 \%)$ were put into the mixture. Later, the outcome was filtered, washed with $5 \%$ of $\mathrm{HCl}$ solution and methanol several times, and then dried in vacuum oven. Finally, graphite oxide was dispersed in deionized water under sonication for $40 \mathrm{~min}$ to prepare 0.5 $\mathrm{mg} / \mathrm{mL}$ solution of exfoliated GO for LBL self-assembly.

\subsection{Fabrication of GO/XNBR film}

Firstly, the substrates of glass slides and silicon wafers were cleaned in "Piranha" solution (7:3 v/v of concentrated $\mathrm{H}_{2} \mathrm{SO}_{4}: 30 \% \mathrm{H}_{2} \mathrm{O}_{2}$ ) for half an hour and washed with generous water, then dried in a steam of nitrogen. The multilayer films were constructed on the substrates by sequential adsorption of the positively charged PEI and the negatively charged GO and XNBR 
latex. The substrates were immersed in a PEI aqueous solution $(2 \mathrm{mg} / \mathrm{mL})$ for 5 min to get a positively charged surface, then rinsed with deionized water and dried by blowing $\mathrm{N}_{2}$ gas. Then the PEI-precoated substrates were then immersed in XNBR latex aqueous solution $(2 \mathrm{mg} / \mathrm{mL})$ for $5 \mathrm{~min}$. Then the substrates were heated at $120{ }^{\circ} \mathrm{C}$ for $2 \mathrm{~min}$ to make the water vapor rapidly so latex articles gradually contacted and fused to a successive film layer. Afterwards, the substrates were re-immersed in PEI solution for 5mins, then rinsed and dried. After that, the substrates were immersed in the as-prepared GO dispersion for $5 \mathrm{~min}$ and rinsed with deionized water and dried again. Desired multilayered films of $(\mathrm{PEI} / \mathrm{XNBR} / \mathrm{PEI} / \mathrm{GO})_{\mathrm{n}}(\mathrm{n}$ represents the number of deposition cycles) were obtained by repeated deposition cycles of the above mentioned alternating of XNBR latex, PEI and GO dispersion. The free standing films were got by immersing the substrates in $0.5 \% \mathrm{HF}$ aqueous solution and rinsed by deionized water. Then the resulting films were dried in room temperature for 24 hour before characterization. The simple schematic representation of the assembling process and the target multilayer film structure were schematically indicated in Fig. 1. During the LBL electrostatic self-assembly process, negatively charged carboxyl groups of XNBR latex and GO sheets can be adsorbed by positively charged amino groups from PEI molecules through electrostatic attraction. After the assembled films heated by hot plate, part of the ionic bonds between XNBR latex, PEI and GO changed into covalent amide bonds. Finally, the multilayered rubber/graphene oxide films were fabricated with the structure of alternating GO sheets and XNBR latex layer.

\subsection{Characterization}

The growth of film assembly was monitored by ultraviolet (UV)-visible spectroscopy (HITACHI, U-3900H). The morphology of the surface and cross section of the films were 
investigated by field emission scanning electron microscopy (FESEM, Hitachi SEM 4800). The glass transition temperature was investigated using a Mettler-Toledo differential scanning calorimeter (DSC). All samples were cooled to $-150{ }^{\circ} \mathrm{C}$ at $10{ }^{\circ} \mathrm{C} / \mathrm{min}$ and reheated up to $100{ }^{\circ} \mathrm{C}$ at $10{ }^{\circ} \mathrm{C} / \mathrm{min}$. Thermal gravity analysis (TGA) test was developed by a thermal gravimetric analyzer of Mettler-Toledo with a heating interval ranging from $30-650{ }^{\circ} \mathrm{C}$ (heating rate 10 ${ }^{\circ} \mathrm{C} / \mathrm{min}$ ). Atomic force microscopy (AFM) images of thicknesses and surface size of GO were characterized using an (Bruker) AFM microscope in tapping mode. Fourier transform infrared spectra (FTIR) were conducted on a Bruker Tensor 27 spectrometer. All the spectra were obtained at a resolution of $4 \mathrm{~cm}^{-1}$ in the wavenumber range of $600-4000 \mathrm{~cm}^{-1}$. The chemical composition of graphite and GO were determined by X-ray photoelectron spectroscopy (XPS). XPS measurements were carried out on an ESCALAB 250 XPS system (Thermo Electron Corporation, USA) with an Al Ka X-ray source (1486.6 eV photons). The core-level signals were obtained at a photo electron take off angle of $45^{\circ}$ with respect to the sample surface. The $\mathrm{X}$-ray source was run at a reduced power of $150 \mathrm{~W}$. The pressure in the analysis chamber was maintained at $10^{-8}$ Torr or lower during each measurement. All binding energies (BEs) were referenced to the $\mathrm{C} 1 \mathrm{~s}$ hydrocarbon peak at $284.6 \mathrm{eV}$ to compensate for surface charging effects. X-ray diffraction (XRD) measurements were tested by using a Rigaku D/max 2500 VB2+PC diffraction with $\mathrm{Cu} \mathrm{K} \alpha$ radiation $\left(\lambda=0.154 \mathrm{~nm}\right.$, scanning rate is $2{ }^{\circ} \mathrm{C} / \mathrm{min}$ ). Tensile tests were carried out by the tensile instrument of Instron 11185 (Instron Corporation, American), with a crosshead speed of $2 \mathrm{~mm} / \mathrm{min}$ at ambient temperature. The electrical conductivity of samples was measured with a four-probe conductivity test meter (RTS-9, China, Guangzhou) at ambient temperature. 


\section{Result and discussion}

\subsection{Characterization of GO}

With many oxygen-containing functional groups, graphene oxide (GO) sheets can be well dispersed in water after ultrasonic for $40 \mathrm{~min}$. Fig. 2(b) exhibits a tapping-mode AFM image of GO sheets deposited onto a mica substrate from an aqueous dispersion with a concentration of $0.02 \mathrm{mg} / \mathrm{ml}$. AFM images show that most GO sheets had heights of $\sim 1.3 \mathrm{~nm}$, which is consistent with $\mathrm{Li}$ and her co-workers' result [13]. This fact reveals characteristics of fully exfoliated GO sheets.

Fig. 3(a) shows the XRD patterns of natural graphite and graphite oxide. The diffraction peak in the XRD pattern of graphite oxide is appeared at $11.4^{\circ}$, corresponding to the repeating interlayer spacing of $0.78 \pm 0.1 \mathrm{~nm}$. It is significantly larger than that of pristine graphite (about $0.34 \mathrm{~nm}$ ), owing to the intercalations of oxide containing groups.

From the FTIR spectra of Fig. 3(b), we can also get the proof of the successful product of graphite oxide. The newly absorption peak of $1731 \mathrm{~cm}^{-1}$ is attributed to the carbonyl group $(\mathrm{C}=\mathrm{O})$ stretching vibration. Besides the absorbance peaks around $3432 \mathrm{~cm}^{-1}$ of hydroxyl group and $1400 \mathrm{~cm}^{-1}$ of $\mathrm{O}-\mathrm{H}$ deformation of graphite oxide was larger than those of graphite, which provides clear evidence that graphite was normally oxidized.

The result can be further confirmed by the XPS C1s core level spectra of both natural graphite and graphite oxide, which can be seen in Fig. 4. The C1s XPS spectrum of graphite oxide clearly indicates a considerable degree of oxidation with four components corresponding to carbon atoms in different functional groups: non-oxygenated ring $\mathrm{C}\left(\mathrm{C}-\mathrm{C}\right.$ of $\mathrm{sp}^{2}$ carbon, 284.6 $\mathrm{eV}), \mathrm{C}$ in $\mathrm{C}-\mathrm{O}$ bonds $(286.6 \mathrm{eV})$, carbonyl $\mathrm{C}(\mathrm{C}=\mathrm{O}, 287.5 \mathrm{eV})$, and carboxylic acid carbon 
$(\mathrm{O}-\mathrm{C}=\mathrm{O}, 289.5 \mathrm{eV})$. The elemental analysis illustrates that $\mathrm{C} / \mathrm{O}$ atomic ratio (2.5) of graphite oxide is much lower than that (20.7) of pristine graphite, which demonstrates the oxidation of natural graphite.

\subsection{Morphology and structure of multilayer films}

The successive construction of LBL self-assembled multilayer films has been monitored by using UV-vis absorption spectroscopy after each deposition cycle of GO. Fig. 5 shows the $\mathrm{UV}$-vis adsorption spectra of the (PEI/XNBR/PEI/GO $)_{\mathrm{n}}(\mathrm{n}=1-10$, number of the deposition cycles) films on quartz slides. An absorption peak at around $227 \mathrm{~nm}$ is the characteristic peak of GO [48]. The linear increase of spectra intensity in the peak absorbance at $227 \mathrm{~nm}$ confirms that the deposition of LBL procedure is very uniform, which can be seen in the insert corner of Fig. 5.

It can be seen that the cross-section of the (PEI/XNBR/PEI/GO $)_{30}$ film exhibits a similar layered structure, as shown in Fig. 6. The film is dense and has a uniform thickness of about $5 \mu \mathrm{m}$, which is basically in accordance with 30 times diameter of the XNBR latex. It can be seen in Fig. 2(a) that the average diameter of the latex particle is about 100-200 nanometers. From the right higher magnification image, we can see the apparent bedded structure of the cross-section of the free standing film, revealing a high degree of ordering GO sheets in XNBR latex.

Fig. 7 exhibits the surface morphology of the $(\mathrm{PEI} / \mathrm{XNBR} / \mathrm{PEI} / \mathrm{GO})_{5}$ film. It can be seen that latex layer is covered with sheet-shaped folds, which confirmed the successful assembly of GO layer. After heat treatment, XNBR latex particles gradually mixed together and became a continuous rubber film layer. Firstly, the ends of the molecular chains and segments in the 
surface of the latex can realize mutual motion and diffusion by thermal treatment. Then, with evaporation of the water contained in the latex, the XNBR latex particles gradually contacted with each other. With further remove of the moisture, latex particles progressively approached each other and engendered deformation. Finally, accompanied by the protective layer's rupture, the expansion contact region of the latex particles fused with each other to achieve a continuous monolayer film. Since the sizes of latex particles vary between $100 \mathrm{~nm}$ to $200 \mathrm{~nm}$, therefore, the surface of the obtained multilayer film is rough to some extent.

\subsection{FTIR of the multilayer film}

The FTIR spectra of pure XNBR film and (PEI/XNBRL/PEI/GO) $)_{30}$ film are shown in Fig. 8. For the spectrum of pure XNBR film, the broad band at $3100 \sim 3600 \mathrm{~cm}^{-1}$ is due to the $\mathrm{O}-\mathrm{H}$ stretching in $\mathrm{H}-\mathrm{O}-\mathrm{H}$, and the peaks at $2924 \mathrm{~cm}^{-1}$ and $2854 \mathrm{~cm}^{-1}$ correspond to the presence of $-\mathrm{CH}_{2}-$ bond. Besides, the absorption peak at $2239 \mathrm{~cm}^{-1}$ belongs to the stretching of $-\mathrm{CN}$. As for the spectrum of LBL film, the strengthened peak intensity at $1647 \mathrm{~cm}^{-1}$ is attributed to the carbonyl stretching $(\mathrm{C}=\mathrm{O})$ in $\mathrm{CONH}$ amide [49]. Moreover, it can be seen the newly appeared peaks of $1306 \mathrm{~cm}^{-1}$ and $1519 \mathrm{~cm}^{-1}$ which are corresponding to the combination of the $\mathrm{C}-\mathrm{N}$ stretching and $\mathrm{N}-\mathrm{H}$ bending vibration of amide bonds. Thus we can get the conclusion that thermal treatment of the LBL film may leads to the formation of amide bonds between the amino groups of PEI and the carboxyl group on the surface of XNBR latex and GO sheets.

\subsection{Thermal properties of the multilayer film}

DSC was used to compare the glass transition temperature (Tg) of pure XNBR film and the LBL assembled film (PEI/XNBRL/PEI/GO) ${ }_{30}$. As shown in Fig. 9, compared with that of pure XNBR film, Tg of the LBL film has an increase from -15.5 to $-10{ }^{\circ} \mathrm{C}$. This increase can be 
partially attributed to the influence of the ionic bonding interaction among PEI, XNBR and GO. Besides, PEI is used as one of the LBL partners due to its terminal $-\mathrm{NH}_{2}$ and backbone $-\mathrm{NH}$ groups, which can initiate chemical bonds with groups of carboxyl from both GO and XNBR latex. The cross-linking of GO-PEI-XNBR was achieved by heating the films to $120{ }^{\circ} \mathrm{C}$ after each deposition of the XNBR latex layer, resulting in the amide bonds between PEI, XNBR and GO, which complemented the intrinsic ionic bonding of the LBL films [50]. Formation of the amide bonds has been proved by above FTIR spectrum of the LBL film. Chemical bonds increases the connectivity of the XNBR latex's matrix with GO sheets, thus hinders the mobility of the rubber molecular chain, leading to the increase of Tg of the LBL film.

Fig. 10 shows the TGA curves of (PEI/XNBR/PEI/GO) ${ }_{30}$ film and XNBR latex film, which are employed to search for the thermal behavior difference between pure XNBR latex film and LBL film. As for the LBL film, it can be observed that when the temperature is below $100{ }^{\circ} \mathrm{C}$, there is hardly any weight loss which means that there is not much absorbed water. A weight loss of $15.6 \%$ can be observed from the stage of 100 to $400{ }^{\circ} \mathrm{C}$, corresponding to the thermal decomposition of labile oxygen-containing functional groups on GO sheets [51] and chain degradation of PEI molecules [52]. From the curve of pure XNBR latex film, it can be seen that when the temperature is above $354{ }^{\circ} \mathrm{C}$ there is a sharp decrease which means that the XNBR chains begin to degrade. Both films show nearly no weight loss when the temperature is above $500^{\circ} \mathrm{C}$. The residual mass of LBL film is about $24.3 \%$, which is attributed to the ash content and graphite product. Getting rid of the $10.3 \%$ residual ash from pure XNBR film, the remaining $14 \%$ weight loss is belonging to the graphite product. As reported before, the overall weight loss of GO is about $46 \%$ at $30-700{ }^{\circ} \mathrm{C}$ [51], which means that GO is about $30 \%$ mass 
proportion in the LBL film.

\subsection{Mechanical and electrical properties of the multilayer film}

Table 1 exhibits a significant enhancement in mechanical properties of the LBL assembling GO/XNBR multilayer film: that is, a $192 \%$ improvement of tensile strength and a $215 \%$ increase of elastic modulus compared with pure XNBR film. However, the data clearly show that the mechanical properties do not change so much, by adding of pure PEI. The increase in mechanical performance of $(\mathrm{PEI} / \mathrm{XNBR} / \mathrm{PEI} / \mathrm{GO})_{30}$ film can be attributed to the regular layer arrangements with enhanced interaction between GO and XNBR bound through PEI and a high degree of orientation of GO sheets, which lead to much more efficient stress transfer between the rubber phase and the stiff GO sheets.

To reveal the influence of deposition cycles on the electrical conductivity of the thermal reduced $(\mathrm{PEI} / \mathrm{XNBR} / \mathrm{PEI} / \mathrm{GO})_{\mathrm{n}}$ films, the resistances of the films with different deposition cycles were measured, and the results are depicted in Fig. 11. It can be seen that the electrical conductivity of the multilayer films increase from $6.5 \mathrm{E}-4 \mathrm{~S} \cdot \mathrm{cm}^{-1}$ to $8.2 \mathrm{E}-3 \mathrm{~S} \cdot \mathrm{cm}^{-1}$ as their deposition cycles increase from 2 to 30 . We attribute the increase of the electrical conductivity of the multilayer films to the increase of the GO layers.

\section{Conclusions}

The uniform multilayer (PEI/XNBR/PEI/GO $)_{n}$ films with high homogeneity and orientation were successfully fabricated by the layer-by-layer (LBL) assembly technique driven by electrostatic force between alternating cationic-PEI and anionic latex-XNBR and graphene oxide-GO . As compared with pure XNBR-rubber films, thermal stability of the nano-organized composite LBL-film was enhanced, with a $\mathrm{T}_{\mathrm{g}}$ increased by $5.3{ }^{\circ} \mathrm{C}$. The multilayer 
rubber/graphene oxide film has ordered arrangement of GO sheets and XNBR latex layers, which exhibits a significant improvement in mechanical properties, namely, $192 \%$ increase of tensile strength and $215 \%$ increase of elastic modulus. The increase in tensile strength of LBL film is attributed to the orientation of GO sheets and the combination of amide and ionic bonds between GO sheets and XNBR layers, which result in a high efficient load transfer between rubber phase and stiff graphene sheets. Besides, the electrical conductivity of the film reaches 8.2E-03 S $\mathrm{cm}^{-1}$ after thermal reduction making promises for its potential use as an elastomeric conductive material.

\section{Acknowledgment}

This work is supported by the National Basic Research Program of China 2015CB654700 (2015CB654704), the Foundation for Innovative Research Groups of the NSF of China (51221002), the National Natural Science Foundation of China (51333004 and 51403015) and the start-up funding of Beijing University of Chemical Technology (BUCT) for excellent introduced talents. YL thanks support by Russian Science Foundation, grant 15-12-20021.

\section{References}

[1] Novoselov KS, Geim AK, Morozov SV, Jiang D, Zhang Y, Dubonos SV, et al. Electric field effect in atomically thin carbon films. Science 2004; 306(5696): 666-9.

[2] Lee CG, Wei XD, Kysar JW, Hone J. Measurement of the elastic properties and intrinsic strength of monolayer graphene. Science 2008; 321(5887): 385-8.

[3] Gómez Navarro C, Burghard M, Kern K. Elastic properties of chemically derived single graphene sheets. Nano Lett 2008; 8(7): 2045-9.

[4] Du X, Skachko I, Barker A, Andrei EY. Approaching ballistic transport in suspended graphene. Nat Nanotech 2008; 3(8):491-5.

[5] Stoller MD, Park S, Zhu YW, An J, Ruoff RS. Graphene-based ultracapacitors. Nano Lett 2008; 
8(10): 3498-502.

[6] Areshkin DA, Gunlycke D, White CT. Ballistic transport in graphene nanostrips in the presence of disorder: Importance of edge effects. Nano Lett 2007; 7(1): 204-10.

[7] Guo J, Ren LL, Wang RY, Zhang C, Yang Y, Liu TX. Water dispersible graphene noncovalently functionalized with tryptophan and its poly (vinyl alcohol) nanocomposite. Composites Part B 2011; 42(8): 2130-5.

[8] Uddin ME, Layek RK, Kim NH, Hui D, Lee JH. Preparation and properties of reduced graphene oxide/polyacrylonitrile nanocomposites using polyvinyl phenol. Composites Part B 2015; 80: $238-45$.

[9] Shen JF, Hu YZ, Shi M, Lu X, Chen Q, Chen L, et al. Fast and facile preparation of graphene oxide and reduced graphene oxide nanoplatelets. Chem Mater 2009; 21(15):3514-20.

[10] Pokharel P, Truong QT, Lee DS. Multi-step microwave reduction of graphite oxide and its use in the formation of electrically conductive graphene/epoxy composites. Composites Part B 2014; 64: $187-93$

[11] Mkhoyan KA, Contryman AW, Silcox J, Stewart DA, Eda G, Mattevi C, et al. Atomic and electronic structure of graphene-oxide. Nano Lett 2009; 9(3): 1058-63.

[12] Lu H, Yao Y, Huang WM, Hui D. Noncovalently functionalized carbon fiber by grafted self-assembled graphene oxide and the synergistic effect on polymeric shape memory nanocomposites. Composites Part B 2014; 67: 290-5.

[13] Li D, Müller MB, Gilje S, Kaner RB, Wallace GG. Processable aqueous dispersions of graphene nanosheets. Nat Nanotechnol 2008; 3(2):101-5.

[14] Paredes JI, Rodil SV, Alonso MA, Tascon JMD. Graphene oxide dispersions in organic solvents. Langmuir 2008; 24(19): 10560-4.

[15] Decher, G. Fuzzy nanoassemblies: toward layered polymeric multicomposites. Science 1997; 277(5330): 1232-7.

[16] Ariga K, Lvov Y, Onda M, Ichinose I, Kunitake T, Ultrathin films of inorganic materials (SiO2 nanoparticles, montmorillonite microplates, and molybdenum oxide) prepared by alternate layer-by-layer assembly with organic polyions. J. Applied Clay Sci 1999; 15 (1-2): 137-52.

[17] Alazemi M, Dutta I, Wang F, Blunk RH, Angelopoulos AP. Electrically Conductive Thin Films Prepared from Layer-by-Layer Assembly of Graphite Platelets. Adv Funct Mater 2009; 19(7): 
1118-29.

[18] Gunes F, Shin HJ, Biswas C, Han GH, Kim ES, Chae SJ, et al. Layer-by-layer doping of few-layer graphene film. Acs Nano 2008; 4(8): 4595-600.

[19] Kotov NA, Dékány I, Fendler JH. Ultrathin graphite oxide-polyelectrolyte composites prepared by self-assembly: Transition between conductive and non-conductive states. Adv Mater 1996; 8(8): $637-41$.

[20] Lee DW, Hong TK, Kang D, Lee J, Heo M, Kim JY, et al. Highly controllable transparent and conducting thin films using layer-by-layer assembly of oppositely charged reduced graphene oxides. J Mater Chem 2011; 21(10): 3438-42.

[21] Tang ZY, Kotov NA, Magonov S, Ozturk B. Nanostructured artificial nacre. Nat Mater 2003; 2(6): 413-8.

[22] Zhao X, Zhang QH, Chen DJ. Enhanced mechanical properties of graphene-based poly (vinyl alcohol) composites. Macromolecules 2010; 43(5): 2357-63.

[23] Podsiadlo P. Ultrastrong and stiff layered polymer nanocomposites. Science 2007; 318(5847): 80-3.

[24] Mamedov AA, Kotov NA, Prato M, Guldi DM, Wicksted JP, Hirsch A. Molecular design of strong single-wall carbon nanotube/polyelectrolyte multilayer composites. Nat Mater 2002; 1(3): $190-4$.

[25] Liu S, Ou JF, Li ZP, Yang SR, Wang JQ. Layer-by-layer assembly and tribological property of multilayer ultrathin films constructed by modified graphene sheets and polyethyleneimine. Appl Surf Sci 2012; 258(7): 2231-6.

[26] Sheng KX, Bai H, Sun YQ, Li C, Shi GQ. Layer-by-layer assembly of graphene/polyaniline multilayer films and their application for electrochromic devices. Polymer 2011; 52(24): 5567-72. [27] Hong TK, Lee DW, Choi HJ, Shin HS, Kim BS. Transparent, flexible conducting hybrid multilayer thin films of multiwalled carbon nanotubes with graphene nanosheets. Acs Nano 2010; 4(7): 3861-8.

[28] Li Z, Wang J, Liu XH, Liu S, Ou JF, Yang SH. Electrostatic layer-by-layer self-assembly multilayer films based on graphene and manganese dioxide sheets as novel electrode materials for supercapacitors. J Mater Chem 2011; 21(10): 3397-403. 
[29] Chen JT, Fu YJ, An QF, Lo SC, Huang SH, Hung WS, et al. Tuning nanostructure of graphene oxide/polyelectrolyte LbL assemblies by controlling $\mathrm{pH}$ of GO suspension to fabricate transparent and super gas barrier films. Nanoscale 2013; 5(19): 9081-8.

[30] Zaman I, Kuan H C, Meng Q, et al. A facile approach to chemically modified graphene and its polymer nanocomposites. Adv Funct Mater 2012; 22(13): 2735-43.

[31] Ma J, Meng QS, Michelmore A, Kawashima N, Izzuddin Z, Bengtsson C, et al. Covalently bonded interfaces for polymer/graphene composites. J Mater Chem A 2013; 1(13): 4255-64.

[32] Meng, QS, Jin, J, Wang, R, Kuan HC, Ma J, Kawashima, N, et al. Processable 3-nm thick graphene platelets of high electrical conductivity and their epoxy composites. Nanotechnology 2014; 25(12): 125707.

[33] Araby, S, Meng QS, Zhang, LQ, Kang Hl, Majewski P, Tang YH, et al. Electrically and thermally conductive elastomer/graphene nanocomposites by solution mixing. Polymer 2014; 55(1): 201-10.

[34] Araby S, Saber N, Ma X, Kawashima N, Kang HL, Shen H. Implication of multi-walled carbon nanotubes on polymer/graphene composites. Mater Design 2015; 65: 690-9.

[35] Das A, Kasaliwal GR, Jurk R, Boldt R, Fischer D, Stockelhuber WK, et al. Rubber composites based on graphene nanoplatelets, expanded graphite, carbon nanotubes and their combination: A comparative study. Compos Sci Technol 2012; 72(16): 1961-7.

[36] Araby S, Zaman I, Meng QS, Kawashima N, Michelmore A, Kuan HC, et al. Melt compounding with graphene to develop functional, high performance elastomers. Nanotechnology 2013; 24(16): 165601.

[37] Malas A, Das CK. Effect of graphene oxide on the physical, mechanical and thermo-mechanical properties of neoprene and chlorosulfonated polyethylene vulcanizates. Composites Part B 2015; 79: $639-48$.

[38] Hu HQ, Zhao L, Liu JQ, Liu Y, Cheng JM, Luo J, et al. Enhanced dispersion of carbon nanotube in silicone rubber assisted by graphene. Polymer 2012; 53(15): 3378-85.

[39] Pokharel P, Pant B, Pokhrel K, Pant HR, Lim JG, Lee DS, et al. Effects of functional groups on the graphene sheet for improving the thermomechanical properties of polyurethane nanocomposites. Composites Part B 2015; 78: 192-201.

[40] Wu J, Huang G, Li H, Wu SD, Liu YF, Zheng J. Enhanced mechanical and gas barrier 
properties of rubber nanocomposites with surface functionalized graphene oxide at low content. Polymer 2013; 54(7): 1930-7.

[41] Araby S, Zhang LQ, Kuan HC, Dai JB, Majewski P, Ma J. A novel approach to electrically and thermally conductive elastomers using graphene. Polymer 2013; 54(14): 3663-70.

[42] Sruanganurak A, Tangboriboonrat P. Surface modification of sulphur prevulcanized natural rubber latex sheet via layer-by-layer assembled PMMA particles. Colloid Surface A 2007; 301(1): $147-52$

[43] Ai H, Meng HD, Ichinose I, Jones SA, Mills DK, Lovo YM, et al. Biocompatibility of layer-by-layer self-assembled nanofilm on silicone rubber for neurons. J neurosci meth 2003;128(1): $1-8$.

[44] Ai H, Lvov YM, Mills DK, Jennings M, Alexander JS, Jones SA. Coating and selective deposition of nanofilm on silicone rubber for cell adhesion and growth. Cell biochem biophys 2003; $38(2): 103-14$

[45] Davi CP, Borelli P, Oliveria JrON, Ferreira M. Natural rubber latex LbL films: Characterization and growth of fibroblasts. Journal App Polym Sci 2012; 125(3): 2137-47.

[46] Miyazaki CM. Bending of Layer-by-Layer Films Driven by an External Magnetic Field. Int J Mol Sci 2013; 14(7): 12953-169.

[47] Hummers, Jr WS, Offeman RE. Preparation of graphitic oxide. J Am Chem Soc 1985; 80(6): 1339.

[48] Manga KK, Zhou Y, YanYL, Loh KP. Multilayer hybrid films consisting of alternating graphene and titania nanosheets with ultrafast electron transfer and photoconversion properties. Adv Funct Mater 2009; 19(22): 3638-43.

[49] Shao L, Lutkenhaus JL. Thermochemical properties of free-standing electrostatic layer-by-layer assemblies containing poly (allylamine hydrochloride) and poly (acrylic acid). Soft Matter 2010; 6(14): 3363-9.

[50] Sullivan DM, Bruening ML. Ultrathin, ion-selective polyimide membranes prepared from layered polyelectrolytes. J Am Chem Soc 2001; 123(47): 11805-6.

[51] Villar-Rodil S, Paredes JI. Martínez-Alonso A, Tascon JM. Preparation of graphene dispersions and graphene-polymer composites in organic media. J Mater Chem 2009; 19(22): 3591-3. 
[52] Fang X, Ma H, Xiao SL, Shen MW, Guo R, Cao XY, et al. Facile immobilization of gold nanoparticles into electrospun polyethyleneimine/polyvinyl alcohol nanofibers for catalytic applications. J Mater Chem 2011; 21(12): 4493-501. 


\section{Figure captions}

Fig. 1. (a) The schematic of the main assembly procedure of XNBR latex, PEI and GO sheets; (b) The final architecture diagram of purpose on a substrate of glass slide or silicon wafer.

Fig. 2. (a) SEM image of XNBR latex dispersion in aqueous deposited on the silicon wafer; (b) A typical AFM tapping-mode image of GO sheets deposited onto a mica substrate from an aqueous dispersion, indicating a sheet thickness of about $1.3 \mathrm{~nm}$.

Fig. 3. (a) XRD patterns of natural graphite and graphite oxide; (b) FTIR spectra of natural graphite and graphite oxide.

Fig. 4. C1s core level spectra of (a) natural graphite and (b) graphite oxide.

Fig. 5. UV-vis absorption spectra of multilayer films of $(\mathrm{PEI} / \mathrm{XNBR} / \mathrm{PEI} / \mathrm{GO})_{\mathrm{n}}(\mathrm{n}=1-10)$ on a quartz substrate, $n$ represents the number of deposition cycles. The insert is a plot of absorbance at $227 \mathrm{~nm}$ versus the number of deposition cycles

Fig. 6. Cross-section morphology of free standing film of (PEI/XNBR/PEI/GO) $)_{30}$ with different magnifications

Fig. 7.Surface morphology of $(\mathrm{PEI} / \mathrm{XNBR} / \mathrm{PEI} / \mathrm{GO})_{5}$ film which was assembled on silicon wafer with different magnifications.

Fig. 8. FTIR spectra of pure XNBR film and LBL assembly film of (PEI/XNBRL/PEI/GO) $)_{30}$.

Fig. 9. DSC curves of LBL assembly film of $(\mathrm{PEI} / \mathrm{XNBR} / \mathrm{PEI} / \mathrm{GO})_{30}$ and XNBR latex film.

Fig .10. TGA curves of LBL assembly film of (PEI/XNBR/PEI/GO) $)_{30}$ and XNBR latex film.

Fig. 11. Plot of the electrical conductivity of $(\mathrm{PEI} / \mathrm{XNBR} / \mathrm{PEI} / \mathrm{GO})_{\mathrm{n}}$ films versus the deposition cycles

Table 1. Mechanical properties of pure XNBR film and its LBL assembly films. 
(a)

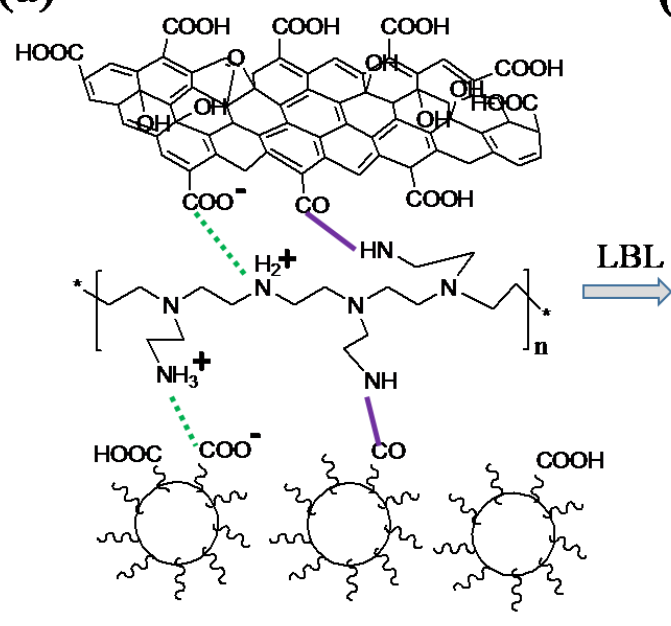

(b)

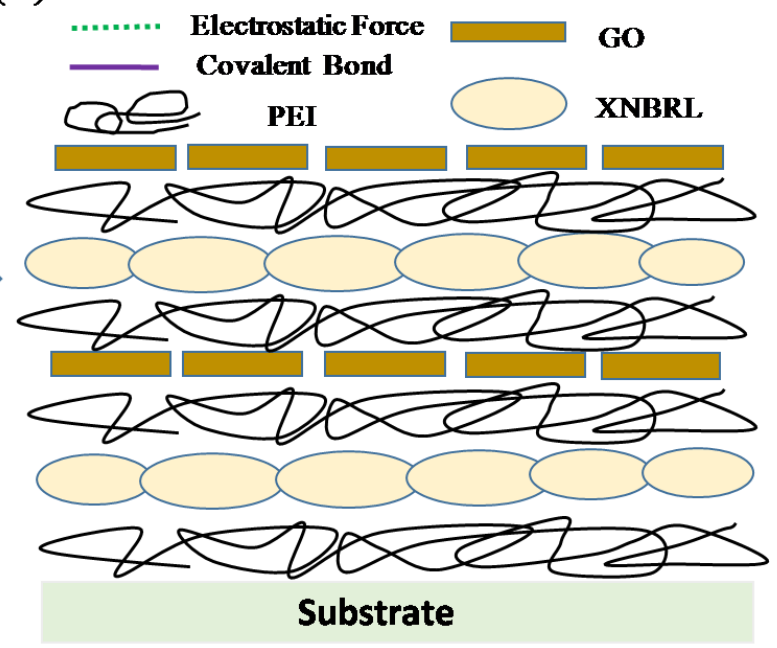

Fig. 1. (a) The schematic of the main assembly procedure of XNBR latex, PEI and GO sheets; (b) The final architecture diagram of purpose on a substrate of glass slide or silicon wafer
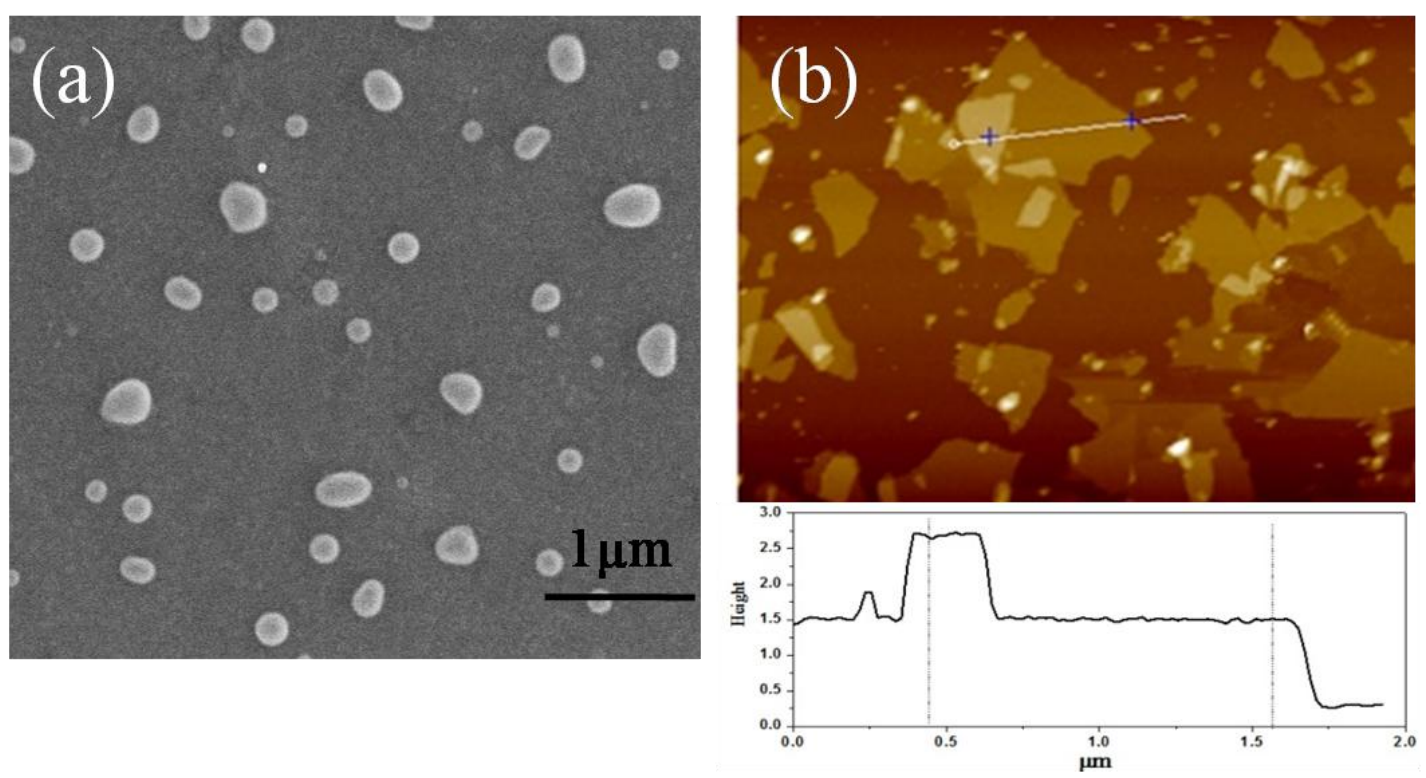

Fig. 2. (a) SEM image of XNBR latex aqueous dispersion deposited onto a silicon wafer; (b) A typical AFM

tapping-mode image of GO sheets deposited onto a mica substrate from an aqueous dispersion, indicating a sheet 

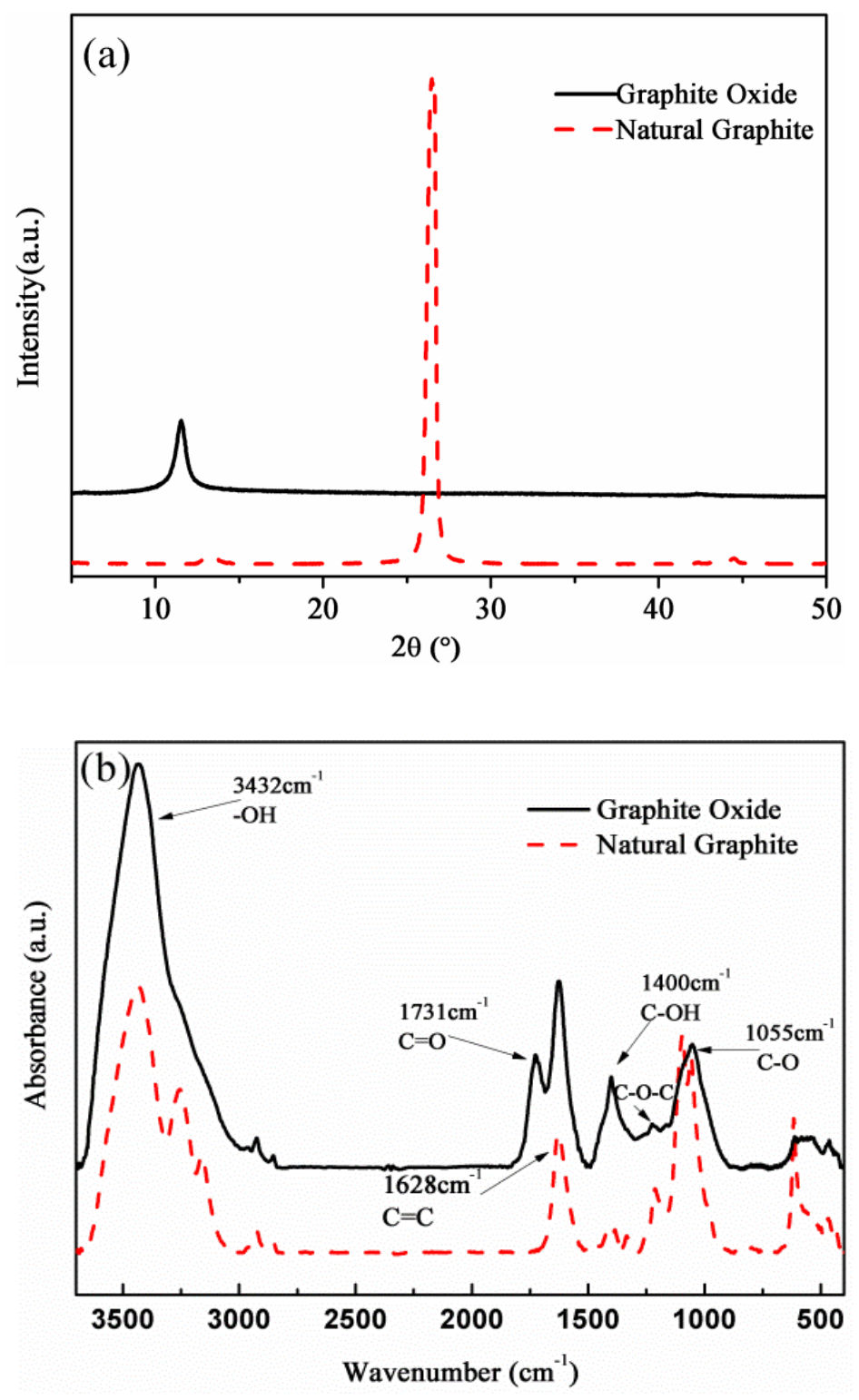

Fig. 3. (a) XRD patterns of natural graphite and graphite oxide; (b) FTIR spectra of natural graphite and graphite oxide. 

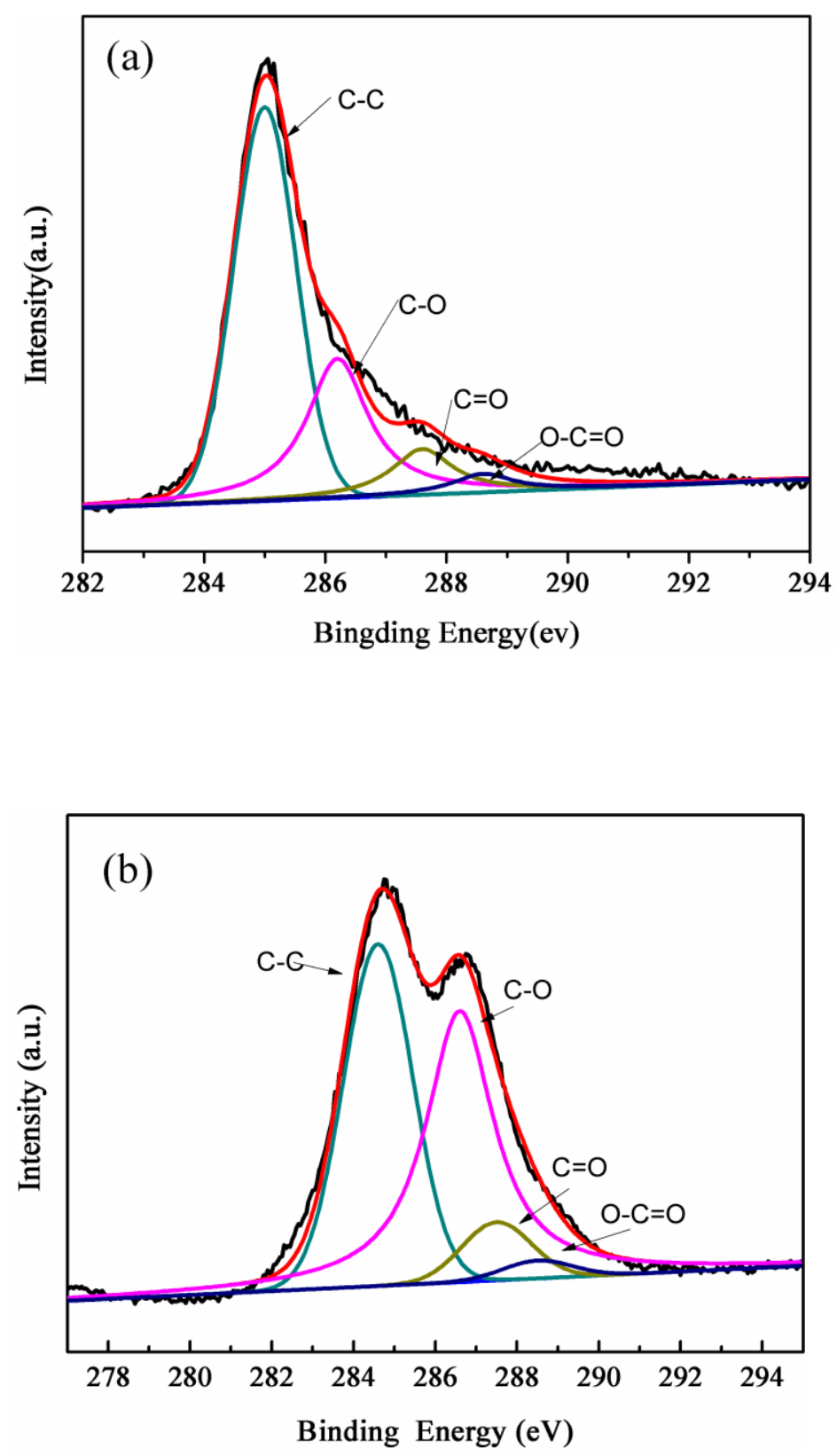

Fig. 4. C1s core level spectra of (a) natural graphite and (b) graphite oxide. 


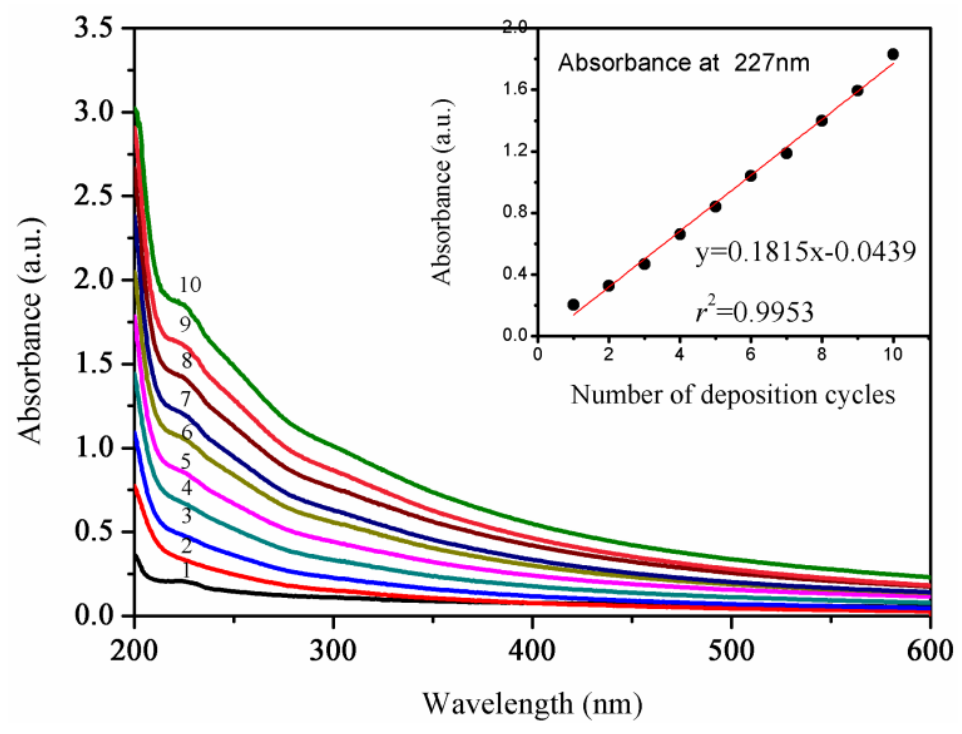

Fig. 5. UV-vis absorption spectra of multilayer films of $(\mathrm{PEI} / \mathrm{XNBR} / \mathrm{PEI} / \mathrm{GO})_{\mathrm{n}}(\mathrm{n}=1-10)$ on a quartz substrate, $n$ represents the number of deposition cycles. The insert is a plot of absorbance at $227 \mathrm{~nm}$ versus the number of deposition cycles.
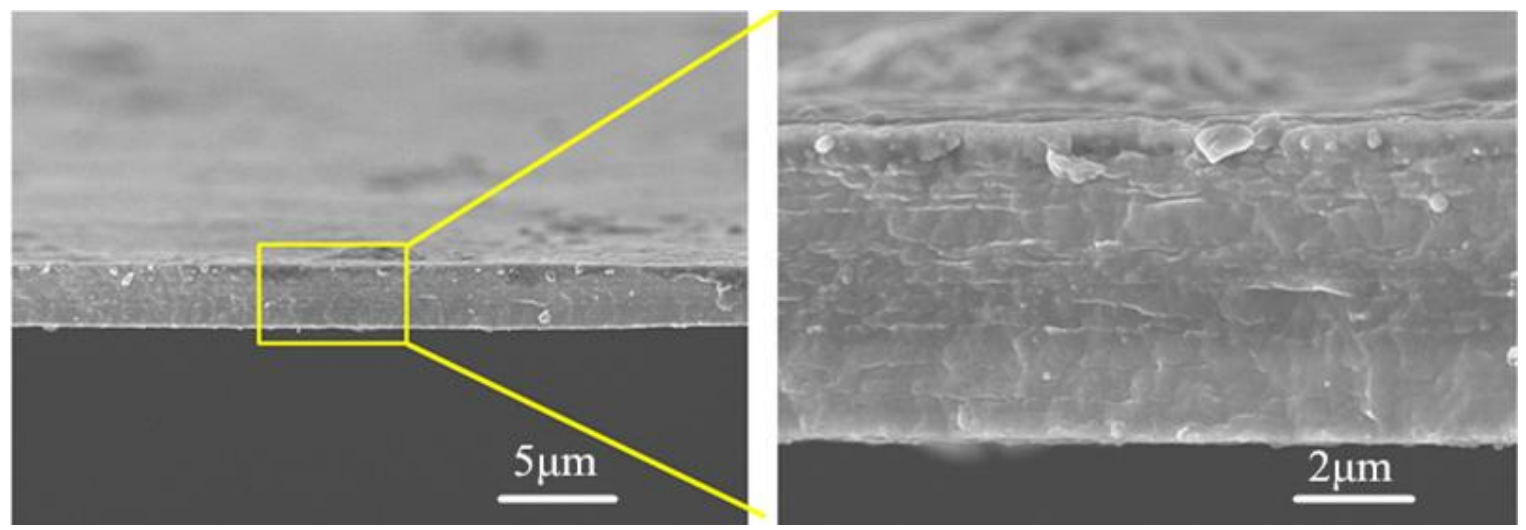

Fig. 6. Cross-section morphology of free-standing film of (PEI/XNBR/PEI/GO $)_{30}$ with different magnifications 

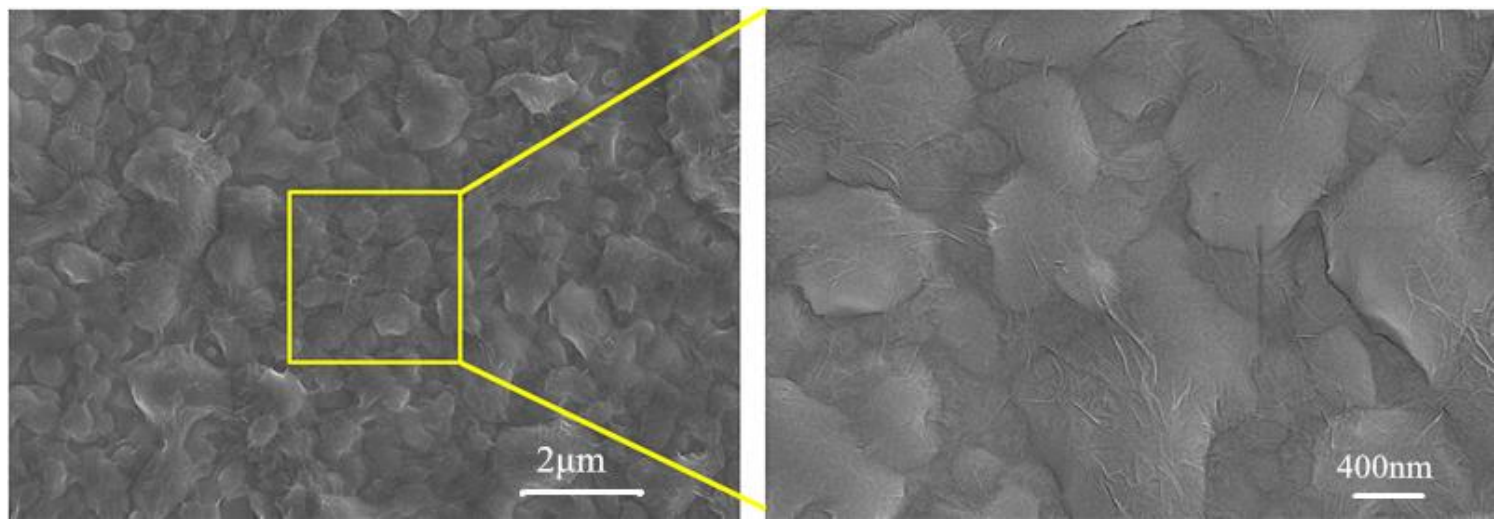

Fig. 7. Surface morphology of $(\mathrm{PEI} / \mathrm{XNBR} / \mathrm{PEI} / \mathrm{GO})_{5}$ film which was assembled on silicon wafer with different magnifications.

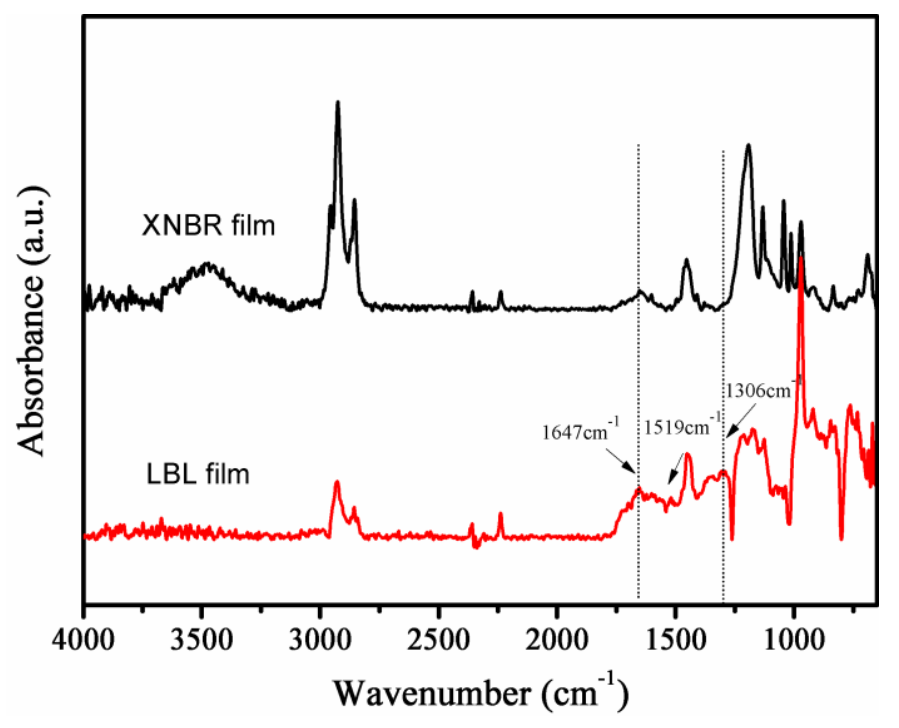

Fig. 8. FTIR spectra of pure XNBR film and LBL assembly film of (PEI/XNBRL/PEI/GO) $)_{30}$. 


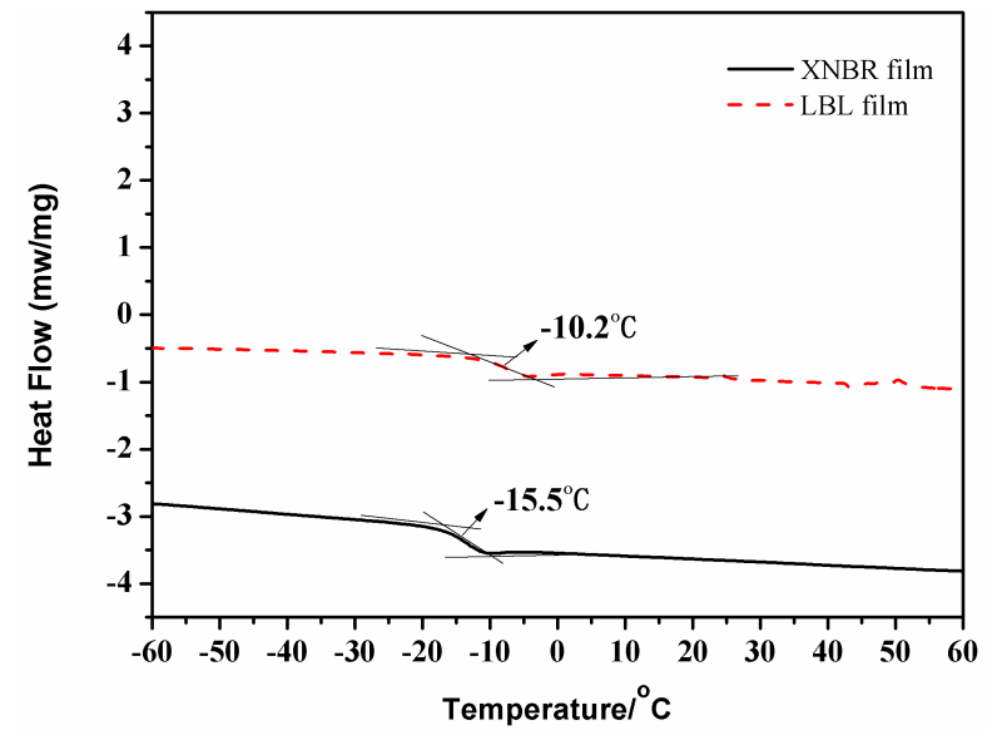

Fig. 9. DSC curves of LBL assembly film of (PEI/XNBR/PEI/GO) $)_{30}$ and XNBR latex film.

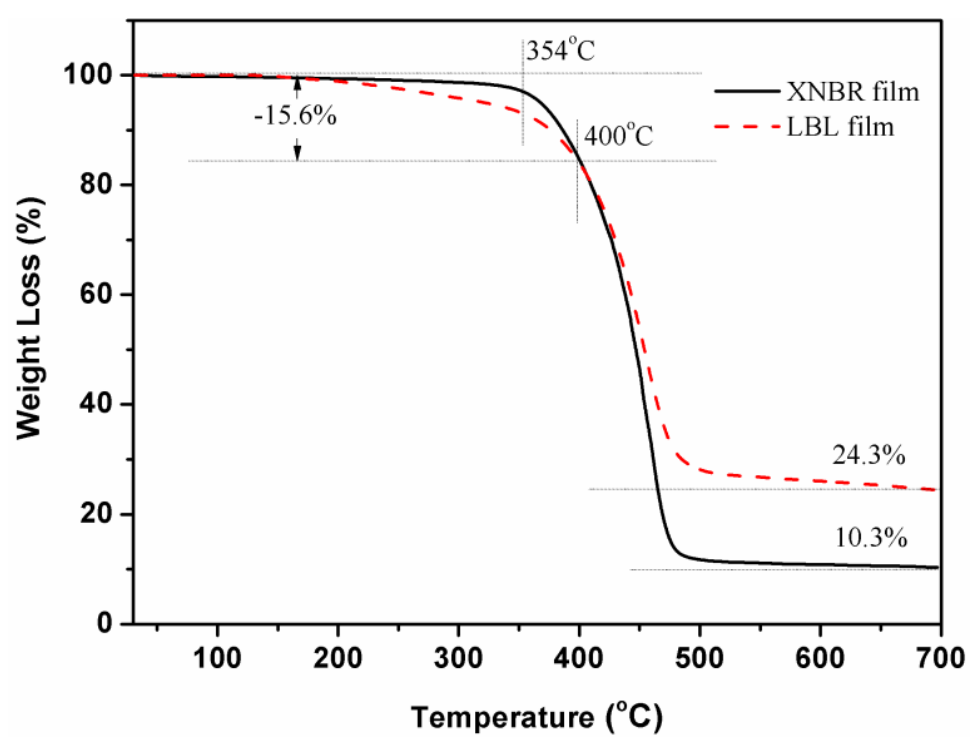

Fig. 10. TGA curves of LBL assembly film of (PEI/XNBR/PEI/GO $)_{30}$ and XNBR latex film. 


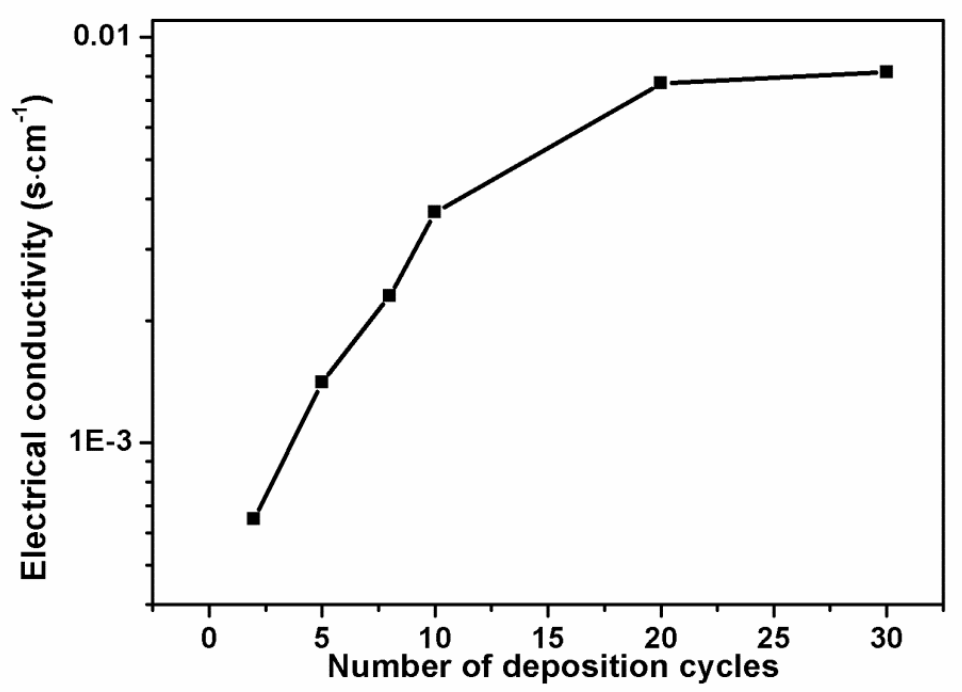

Fig. 11. Plot of the electrical conductivity of (PEI/XNBR/PEI/GO) films versus the deposition cycles

Table 1. Mechanical properties of pure XNBR film and its LBL assembly films.

\begin{tabular}{cccc}
\hline Samples & Tensile Strength & Elastomeric Modulus & Elongation \\
\hline pure XNBR film & $0.73 \mathrm{MPa}$ & $1.2 \mathrm{MPa}$ & $3100 \%$ \\
$(\mathrm{PEI} / \mathrm{XNBR})_{30}$ & $0.78 \mathrm{MPa}$ & $1.4 \mathrm{MPa}$ & $2200 \%$ \\
$(\mathrm{PEI} / \mathrm{XNBR} / \mathrm{PEI} / \mathrm{GO})_{30}$ & $2.3 \mathrm{MPa}$ & $3.5 \mathrm{MPa}$ & $208 \%$ \\
\hline
\end{tabular}

